\title{
FOSTERING INFRASTRUCTURE DEVELOPMENT ALIGNED WITH SUSTAINABLE DEVELOPMENT GOALS
}

\author{
Mohammed Ali Berawi ${ }^{1 *}$, Mustika Sari ${ }^{1}$, Perdana Miraj ${ }^{1}$ \\ ${ }^{1}$ Center for Sustainable Infrastructure Development, Faculty of Engineering, Universitas Indonesia, Depok \\ 16424, Indonesia
}

Infrastructure development plays a crucial role in accelerating the sustainable economic growth and development of a country. The increased provision of public infrastructure can help raise the GDP growth level by lowering production costs, enlarging markets, raising total factor productivity, and facilitating economic activities. Furthermore, infrastructure helps improve the living standards of the people by providing jobs and building the local suppliers' and developers' capabilities, which contribute to reducing poverty and improving development outcomes.

On the other hand, infrastructure is also crucial and lies at the core of efforts to achieve sustainable development. It encompasses many aspects of the Sustainable Development Goals (SDGs), such as health, education, access to energy, as well as clean water and sanitation. The infrastructure improvement is implied in most of the targets of SDGs. The importance of infrastructure must take the sustainable development dimension into account; hence greater efficiencies can be obtained to achieve SDGs successfully.

Despite its potential benefits, infrastructure development that is poorly planned, implemented, or operated brings negative consequences for the society, which is escalated by an overrun budget and ineffective usage. Therefore, an infrastructure system must be developed to meet sustainability needs. Sustainability in infrastructure can be comprehended as how the attributes of the practices, products, services, and resources used in the infrastructure development can contribute to the continuation of ecosystem components and functions for generations in the future. Infrastructure projects must deliver better value by going hand-in-hand with sustainability, projecting its benefits and costs towards both the short-term goals and long-term implications.

In order to be aligned with the dimension of sustainability, infrastructure needs to consider the economic, social, and environmental aspects. In terms of the economic aspect, infrastructure development should contribute to overall growth by supporting inclusivity, boosting productivity, and delivering accessible and affordable services. In terms of the social aspect, infrastructure is supposed to improve livelihoods, enhance human well-being, and remove poverty in all forms. Lastly, in terms of environmental aspects, the development of infrastructure should preserve the natural environment, ecosystems, and the biodiversity within by supporting the use of high-energy efficiency standards and promoting the resource-efficient approach contributing to reducing overall carbon emissions during its lifecycle.

As sustainable infrastructure becomes a cornerstone to achieving the SDGs; therefore, the long-term vision for developing a national infrastructure system informed by SDGs should be ensured. We argue that these visions can be delivered by establishing adaptable plans that include implementing lowcarbon solutions and resource-efficient, ecologically based, and energy-efficient technologies.

\footnotetext{
*Corresponding author's email: maberawi@eng.ui.ac.id DOI: https://doi.org/10.32783/csid-jid.v4i1.236
} 


\section{Sustainable Technologies-related Research}

Technology provides alternative solutions to achieve sustainable development goals. In this edition of the CSID Journal of Infrastructure Development, nine papers dedicated to studies related to sustainable technology are presented.

The first paper, written by B. Susantono and S.H. Li, discussed the experience of Singapore in combating water challenges. Their findings showed that urban water in Singapore has undergone extensive holistic planning, supply and demand management, as well as constant efforts in technology advancement and innovation. Despite current progress Singapore has been developing, the author proposes solutions to tackle water issues in Asian and Pacific countries including diversifying water sources and reducing NRW, increasing energy efficiency and exploring renewable energy, as well as engaging private sector investment.

The second paper, written by R. Shankar and W. Tan, elaborates on the understanding of spatial distribution of monetized road assets using Toll-Operate-Transfer (TOT) model. The author found that the scheme had different results on two project auctions in terms of asset quality, political factor, strategic factor, social factor and project outcome. Their findings highlight the importance of political considerations and experimentation in selecting auction assets. The result also showed that government-controlled auctions produce more favourable outcomes for related parties.

The third paper, written by N.V. Tam, review publications related to public private partnership (PPP) in the infrastructure sector during the last two decades. The author used bibliometric analysis in order to generate targeted results. The author found the PPP publication dramatically increased from 2008 onwards. The author explored four main themes of research on PPP for infrastructure including research on success factors of PPP for infrastructure projects, research on risks of PPP for infrastructure projects, research on financing of PPP for infrastructure projects and research on relationship among parties of PPP for infrastructure projects. Future research direction suggested to focus on social and environmental impact assessment for PPP models development, and performance evaluation criteria for PPP projects long-term viability.

The fourth paper, written by C. Hadu, and E. Ellisa, examined the significance of informality which shapes a compact urban form in the 'desakota' area. 'desakota' is a peri-urban area that suffers environmental degradation in the economy and socio-culture due to poor planning and control from state and local authority. The author used Tangerang - a neighboring area of the capital city of Indonesia as the case study. The findings showed that there is a dialectical relationship between informality and the physical environment that is still a largely neglected issue in peri-urban studies. The article concluded that the informality potents should be considered for designing 'desakota' to maintain its compact form and create a more sustainable urban form and a better urban life.

The fifth paper, written by W. Nwaki, E. Eze and I. Awodele, elaborates major barriers to lean construction application on construction project delivery. The author took Nigeria as the case study, and found some barriers of lean construction that should be dealt with related stakeholders in construction projects. It includes technology and knowledge barrier, leadership and management barrier, culture and complexity barrier, engagement and relationship barriers, financial barriers, and communication barriers. Author further stressed the need to incorporate leadership and management support to improve lean construction knowledge and practice.

The sixth paper, written by D.R. Fatma and Y. Lukito, discusses how Petang Megang reflects the connection of local people to the river and influences the spatial form of the Siak riverside. Petang Megang is known as a tradition to clean and purify the body and soul to welcome the holy month of Ramadan. Currently, the local government has paid more attention to the ceremony by involving more competitions and festivals to attract tourists, but this action limits access of local people to the 
river. Therefore, a balanced solution between accessibility and profitability should be further elaborated.

The seventh paper, written by J. Maina, M. Dagoli, A. Abdulkadir, N. Muhammad, I. Muhammed, B. Yusuf, T. Mtan, and M. Abdulrazaq, investigates satisfaction of dwelling unit attributes, support services and infrastructure within public housing estates across Northern Nigeria. The author argued that residents perceive satisfaction with dwelling unit attributes and infrastructure in terms of design and cost, services and IEQ as well as electricity supply and noise levels. The paper recommends some improvement of public housing related to building quality, indoor environmental quality, and technology adoption.

The eighth paper, written by I. Anum and O.F. Job, ameliorating the negative impact of plastic inclusion for concrete strength behavior through pulverisation and chemical treatment of HighDensity Polyethylene (HDPE). The result illustrated HDPE content beyond $0.5 \%$, restrained hydration takes negative effects on the concrete. It was also shown that the designed compressive strengths of the tested samples were satisfactorily met in all cases indicating improvement in the compressive behaviour of the samples. The author suggested that pulverised HDPE could be used as an admixture in concrete without compromising their compressive strengths.

The ninth paper, written by S. Agarwal, T.P. Nanda, R. Bali and A. Soni, check the feasibility of an Urban Land Data Repository, drawn from the Real Estate Regulation Act 2016, by taking into account Indian four states of Uttar Pradesh, Madhya Pradesh, Haryana, and Maharashtra. The paper details the data points and the rationale for taking them, closing with an analysis of the current data availability for the proposed repository through this policy analysis paper.

We hope that this edition may convey new insight and knowledge that bring benefits to our readers. We welcome any comments or inquiries that you may have concerning the direction and the content of this journal. We also invite you to join our venture by sending your work for future consideration.

Warmest regards from Editorial Office,

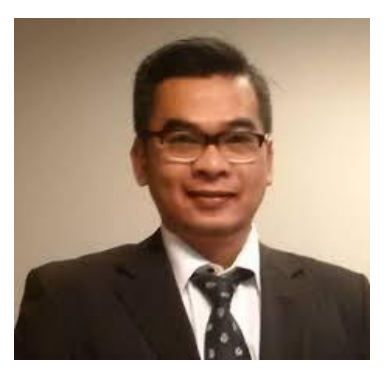

Dr. Mohammed Ali Berawi Editor-in-chief

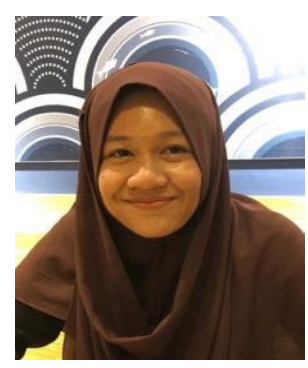

Mustika Sari Managing Editor

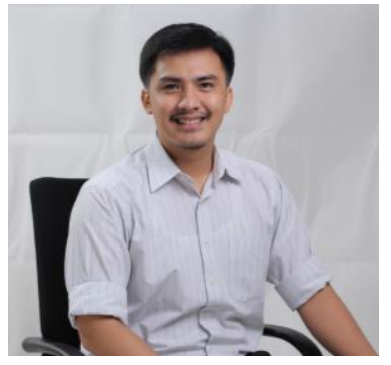

Perdana Miraj Managing Editor 